\title{
THE IMPACT OF MERIDONAL WIND TO THE MOISTURE TRANSPORT AND WEATHER FORMATION IN WEST INDONESIA ON FEBRUARY 2014
}

\author{
Mahardiani Putri Naulia Batubara \\ Badan Meteorologi Klimatologi dan Geofisika Jakarta Jalan Angkasa I nomor 2 Kemayoran \\ Email : mahardianiputri@gmail.com
}

\begin{abstract}
Abstrak
Angin merupakan pergerakan massa udara yang disebabkan karena perbedaan sifat fisis benua dan samudera. Dalam pergerakannya, angin akan mentransfer kelembapan, momentum, dan juga fluks yang akan berpengaruh terhadap pembentukan cuaca di daerah yang akan dilaluinya. Angin meridional merupakan angin yang bergerak secara vertikal dari utara ke selatan atau sebaliknya. Sedangkan transpor kelembapan merupakan jumlah uap air yang ditransfer per satu volume massa udara dengan rentangan nilai transpor uap air yang berbeda-beda. Ketersediaan uap air merupakan salah satu komponen utama dalam pembentukan awan-awan konvektif penghasil hujan. Pada Februari 2014, kondisi anomali cuaca terjadi di wilayah Indonesia bagian barat, dimana terjadi penurunan curah hujan secara drastis sehingga wilayah di Indonesia bagian barat menjadi sangat kering. Jika dibandingkan dengan klimatologisnya, kondisi cuaca yang terbentuk pada Februari 2014 merupakan kali pertama yang terjadi di wilayah Indonesia bagian barat. Secara geografis di sebelah utara Indonesia bagian barat berbatasan dengan Benua Asia dan Laut Cina Selatan. Sehingga pada saat terjadi angin monsun ataupun seruakan dingin yang biasanya terjadi pada bulan Desember, Januari, dan Februari, akan ditransfer ke wilayah Indonesia bagian barat. Untuk itu, pada tulisan ini akan dibahas mengenai ketersediaan uap air pada Februari 2014 dan besar uap air yang ditransfer dalam bentuk kelembapan. Data yang digunakan dalam penelitian ini adalah data dari European Centre for Medium-Range Weather Forecast (ECMWF) dengan resolusi 0,1250 x 0,1250 dan akan diolah dengan menggunakan aplikasi Grid Analysis and Display System (GrADS).
\end{abstract}

Kata kunci: Angin meridional, transpor kelembapan, curah hujan

\begin{abstract}
Wind is the movement of air masses due to the physical differences between continent and ocean. In that motion, wind will transfer the moisture, momentum, and also flux that will affect to the weather formation in the region that will be passed. Meridional wind is a wind with vertical movement from north to the south and vice versa. Meanwhile, moisture transport is the total of water vapor which is transfered by one air mass volume in a different range. The availability of water vapor is one of the main components in the formation of convective clouds in producing rain. In February 2014, weather anomaly occurred in western Indonesia, where the rainfall declined drastically and it became so dry in a wet month. In a comparison to its climatology, the weather condition that formed in February 2014, is the first time occurred in western Indonesia. Geographycally, in the northern of west Indonesia is bordered primarly to Asia continent and South China Sea, so that in monsoon period or cold surge
\end{abstract}


period that usually happened on December, January, and February, the cold air masses will be transfered to west Indonesia. For that reason, this paper will discuss about the availability of water vapor in February 2014 and the amount of moisture transport. The data that will be used in this observation is data from the European Centre for Medium-Range Weather Forecast (ECMWF) with resolution 0,1250 x 0,1250 and will be processed by the Grid Analysis and Display System (GrADS) application.

Keywords: Meridional wind, moisture transport, rainfall

\section{PENDAHULUAN}

Secara umum Indonesia memiliki dua musim yaitu hujan dan kemarau. Musim hujan berlangsung sekitar bulan Oktober hingga Maret dengan puncaknya pada bulan Desember hingga Februari yang bertepatan dengan periode monsun dari Benua Asia pada musim dingin. Sementara itu musim kemarau berlangsung sekitar bulan April sampai September, dengan periode angin monsun dari Benua Australia pada musim dingin (Sulistya,1995 dalam Sofiati, 2012).

Walaupun pergantian musim di Indonesia sangat dipengaruhi oleh aktifitas monsun (Sribimawati dkk.,1999), namun sifat musim tidak selalu sama dengan normalnya. Dapat ditemui periode dengan curah hujan di atas normal, maupun di bawah normal.

Beberapa fakta menunjukkan bahwa awal musim hujan dan musim kemarau tidaklah selalu sama setiap tahunnya. Panjang musim hujan dan musim kemarau juga tidak sama untuk seluruh wilayah Indonesia. Kondisi ini menunjukkan bahwa musim tidak hanya dipengaruhi oleh monsun (yang hampir tetap) saja tetapi juga dipengaruhi oleh faktor lain yang berinteraksi dengan monsun untuk membentuk musim di Indonesia. (Swarinoto dkk. 1998).

Terdapat dua musim monsun utama yang sangat dominan di wilayah Indonesia yaitu Monsun Timur Laut pada bulan Desember sampai dengan Maret dan Monsun Barat Daya pada bulan Juni sampai dengan September (Prawoto dkk., 2011). Pada saat monsun dingin Asia, di wilayah Indonesia bagian barat sering kali terjadi kondisi cuaca yang lebih buruk seperti hujan dengan intensitas lebat. (Setiawan, 2014). Hujan - hujan dari awan konvektif mendominasi kejadian cuaca di wilayah Indonesia bagian barat karena persediaan uap air yang melimpah dari wilayah perairan yang mengelilingi wilayah tersebut. (Prawoto dkk., 2011)

Kondisi anomali terjadi pada Februari 2014, dimana intensitas curah hujan di hampir seluruh wilayah Indonesia bagian barat menurun drastis hingga $0 \mathrm{~mm}$ selama satu bulan. Dengan kata lain, selama periode Februari 2014, tidak terjadi hujan di wilayah Indonesia bagian barat. Dan pada periode tersebut jugab dianalisis bahwa kondisi El Nino sedang tidak aktif di wilayah Indonesia.

Merujuk pada kondisi anomali yang terjadi pada bulan Fbruari 2014, dimana suplai massa udara terbesar yang sampai di willayah Indonesia, terutama Indonesia bagian barat berasal dari Asia. Untuk itu, pada penelitian ini akan dibahas kondisi angin meridional dan ketersediaan moisture transport di wilayah Asia dan jumlah moisture transport yang sampai ke wilayah Indonesia bagian barat.

Pengaruh angin meridional akan dilihat dengan menampilkan medan angin (streamline) lapisan 925 mb, sedangkan untuk moisture transport akan ditampilkan pada ketinggian 1000 mb sampai 700 mb. Dari analisis akan diperoleh gambaran umum pembentukan cuaca di wilsyah Indonesia bagian barat pada Februari 2014.

Berdasarkan pada peta distribusi curah hujan dan sifat hujan yang dikeluarkan oleh Badan Meteorologi Klimatologi dan Geofisika (BMKG) terlihat bahwa pada Februari 2014, distribusi curha hujan di wilayah Indonesia bagian barat masuk dalam kondisi bawh normal 0-64 \%. Sementara itu, sifat curah hujan menggolongkan hujan yang terjadi pada Februari 2014 tergolong rendah dengan presentasi $0-50 \%$. 


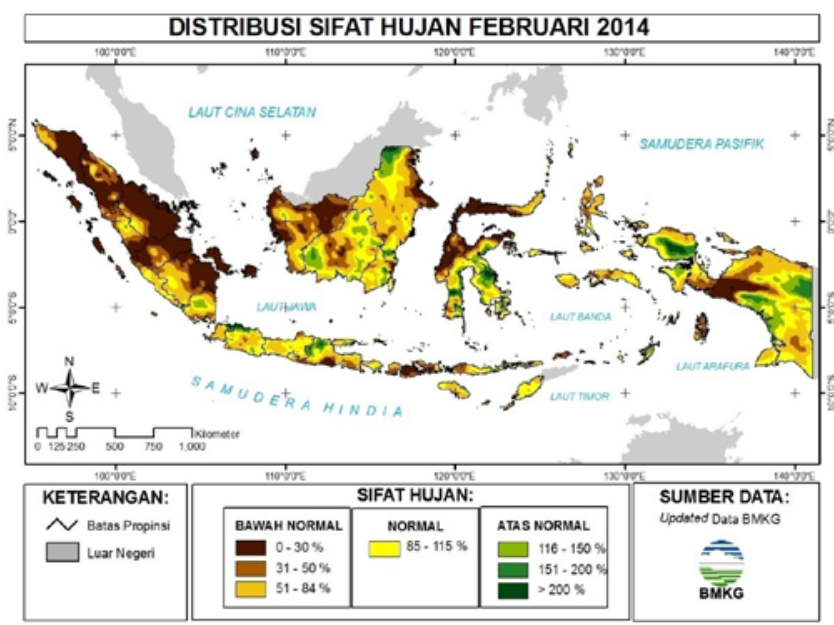

GAMBAR 1 Peta Sifat HujanFebruari 2014 (BMKG,2014)

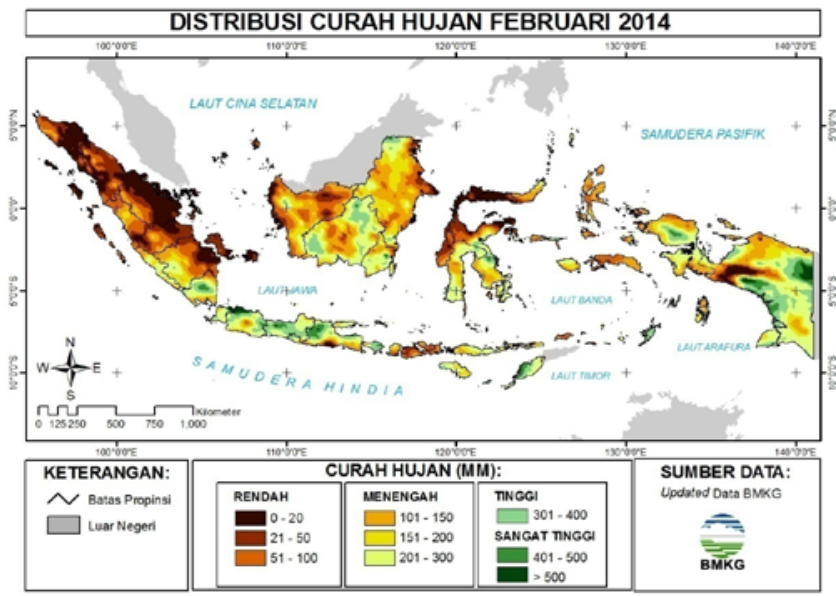

GAMBAR 2 Peta Distribusi Curah Hujan Februari 2014 (BMKG,2014)

\section{METODE PENELITIAN}

Metode penelitian yang digunakan pada tulisan ini ialah analisis kualitatif berdasarkan rentangan nilai dari visualisasi hasil. Data yang digunakan pada penelitian ini adalah data reanalisis dari European Centre for Medium-Range Weather Forecast dengan resolusi $0.125^{\circ}$ x $0.125^{\circ}$. Daerah penelitian pada tulisan ini berada pada koordinat $20^{\circ} \mathrm{LU}-15^{\circ} \mathrm{LS}$ dan $85^{0} \mathrm{BT}-125^{0} \mathrm{BT}$ dan diolah dengan menggunakan aplikasi visualisasi Grid Analysis and Display System (GrADS). Secara rinci langkah-langkah yang digunakan pada penelitian ini adalah :

1. Mengunduh semua data reanalisis yang digunakan, yaitu berupa data angin komponen u dan $\mathrm{v}$, serta kelembapan spesifik (q).

2. Resolusi data yang diunduh yaitu $0,125^{\circ} \times 0,125^{0}$ dengan luas daerah meliputi $30^{\circ} \mathrm{LU}-30^{0}$ LS dan $85^{\circ}$ BT- $180^{\circ}$ BT selama periode Februari 2014.

3. Pengolahan data reanalisis melalui aplikasi Grid Analysis and Display System (GrADS) Data yang diolah dan dianalisis berupa moisture transport dan streamline.

4. Analisis arah dan kecepatan angin yang berhembus pada Februari 2014.

5. Analisis dan interpretasi hasil visualisasi untuk melihat jumlah transpor kelembapan yang tersedia dan yang ditransfer di wilayah Indonesia Bagian Barat.

6. Penarikan kesimpulan pengaruh angin meridional terhadap transpor kelembapan yang berkaitan dengan pembentukan cuaca di wilayah Indonesia bagian barat Februari 2014. 


\section{HASIL PENELITIAN}

\section{Analisis Medan Angin}

\subsection{Analisis Medan Angin Dasarian I}

Pada awal dasarian Februari 2014 terbentuk pusaran siklonik atau vorteks di wilayah pantai barat Sumatera dan barat Australia.
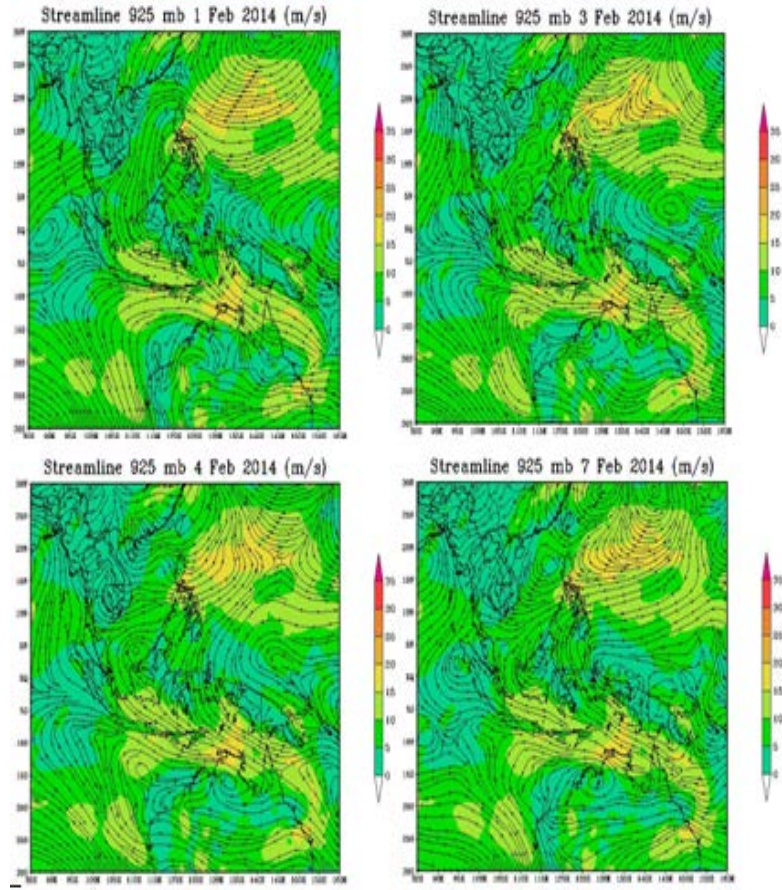

GAMBAR 3 Medan Angin Februari 2014

Vorteks siklonik yang ada di barat Australia bergerak dan sampai ke utara Australiapada akhir dasarian pertama. Tidak seperti vorteks yang terbentuk di Australia, vorteks yang terbentuk di pantai barat Sumatera memiliki daur hidup yang lebih singkat. Pada awal Februari terbentuk daerah netral di selatan Filipina. Selain itu, terlihat adanya pergerakan pusaran siklonik lain yang berasal dari Pasifik menuju utara Papua dan akhirnya punah saat memasuki wilayah Filipina.

Angin yang berasal dari belahan bumi selatan bersama dengan massa udara yang berasal dari Samudera Hindia bergerak memasuki Laut Jawa dan utara Australia dengan kcepatan yang relatif tinggi. Pada gambar 3 terlihat adanya divergensi di wilayah Asia Tenggara, Malaysia dan Kepulauan Riau, dengan kecepatan angin 5-10 m/s.

\subsection{Analisis Medan Angin Dasarian II}

Pada dasarian kedua akan diamati perubahan arah dan kecepatan angin yang terjadi. Berikut tampilan medan angin dasarian kedua Februari 2014 yang tertera pada gambar 4. Pada dasarian kedua terlihat perubahan yang cukup signifikan dengan divergensi angin yang semakin menguat pula. Pada tanggal 17 Februari 2014, divergensi terjadi di Filipina dan wilayah Asia Tenggara sampai Kepulauan Riau. Sedangkan pada tanggal 19 Februari 2014, angin yang masuk ke wilayah Sumatera, khususnya Sumatera barat mengalami perubahan arah, dimana angin bergerak dari arah barat dan membelok menuju utara Jawa.

Selain terjadi variasi angin, pada dasarian kedua ini juga terbentuk banyak pusaran-pusaran angin, baik berupa vorteks maupun pusaran angin siklonik. Di awal dasarian kedua Februari 2014 terbentuk vorteks di selatan Sumatera, selatan Australia, dan utara Papua yang bertahan selama beberapa hari. 
Vorteks yang terbentuk di utara Kalimantan tidak terbentuk lagi pada dasian kedua. Hal ini mengakibatkan angin yang bergerak dari Asia akan membelok di daerah barat Kalimantan.

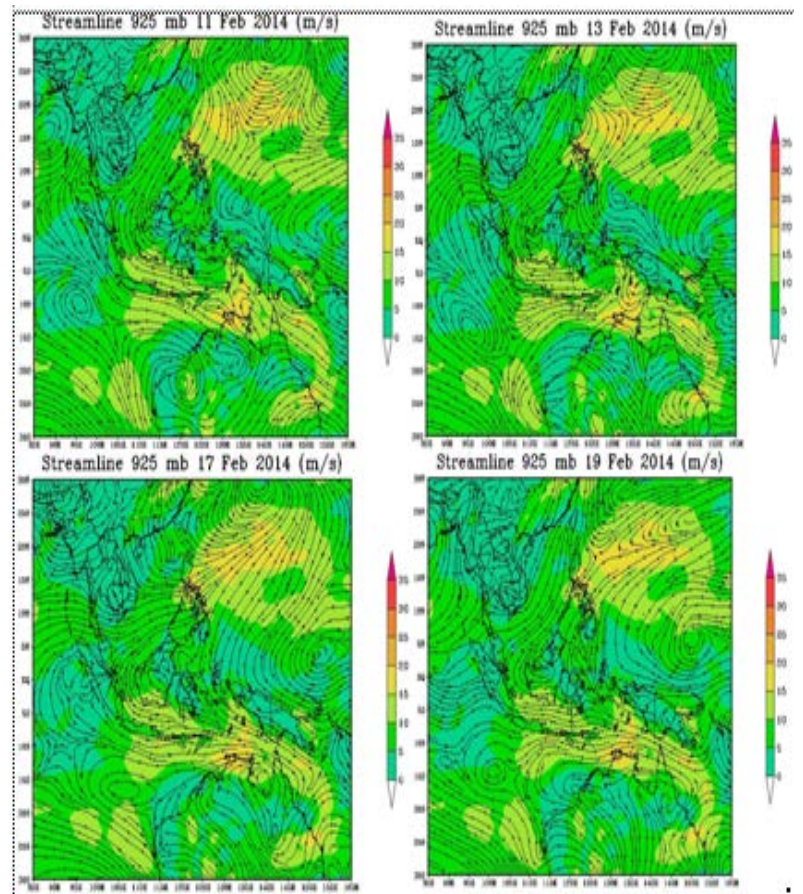

GAMBAR 4. Medan Angin Dasarian II Feb 2014

\subsection{Analisis Medan Angin Dasarian III}

Berdasarkan hasil pengolahan medan angin terlihat bahwa pada dasarian ketiga Februari 2014 tidak terlalu terjadi perubahan yang signifikan. Angin yang bergerak menuju Sumatera kembali berasal dari arah timur laut. Dari awal hingga akhir dasarian ketiga Februari 2014, terlihat bahwa masih terjadi divergensi di wilayah Malaysia, Sumatera bagian utara, dan Kepulauan Riau.
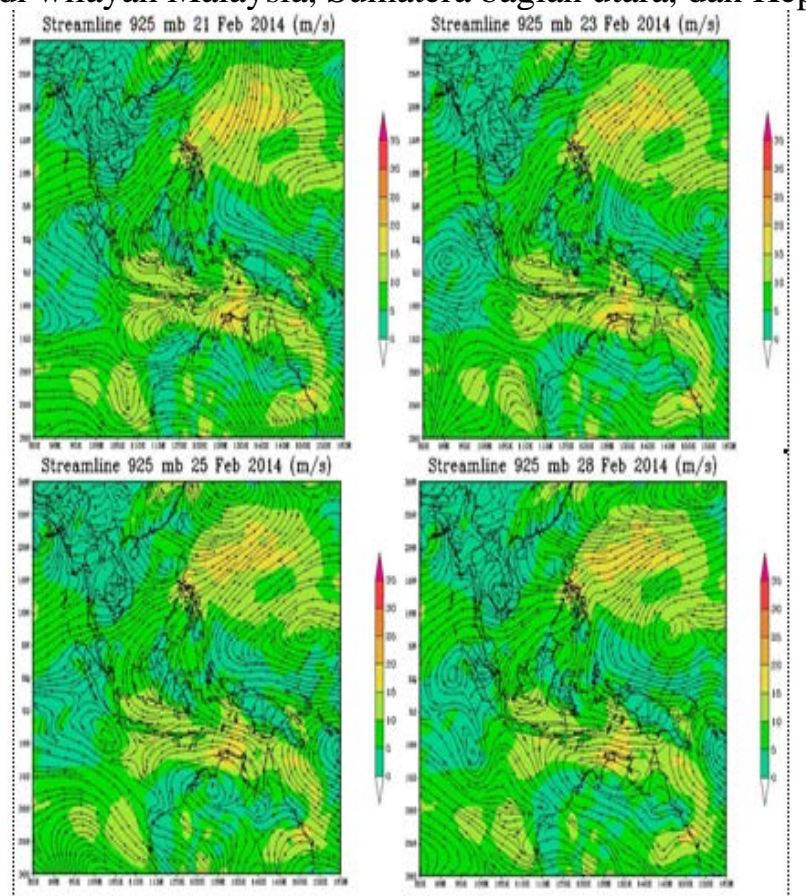

GAMBAR 5 Medan Angin Dasarian III Feb 2014 
Pusaran-pusaran siklonik terbentuk di wilayah utara Australia serta pada koordinat 00-50 LU dan 1500-1550 BT. Pusaran yang terbentuk pada koordinat tersebut terus bergerak hingga mencapai daerah 50-100 LU dan 1400-1450 BT pada akhir dasarian ketiga Februari 2014. Pada pertengahan dasarian ketiga terlihat adanya daerah netral yang terbentuk di pantai barat Sumatera dan selatan Laut Jawa.

Sementara itu, memasuki akhir dasarian ketiga, di pantai barat Sumatera terbentuk dua pusaran siklonik. Fluktuasi pusaran angin terjadi sangat intens di wilayah pantai barat Sumatera. Hal ini dimungkinkan karena pengaruh bukit barisan yang membentang cukup panjang di wilayah Sumatera. Kondisi pada daerah netral akan cenderung stabil dan bercuaca cerah. Kecepatan angin pada dasarian ketiga ini masih sama dengan dasarian pertama dan dasarian kedua Februari 2014.

\section{Analisis Moisture Transport}

Ketersediaan uap air merupakan salah satu komponen utama dalam pembentukan awanawan konvektif untuk menghasilkan hujan. Transpor uap air memiliki peranan yang penting dalam menganalisis dampak dari beberapa gangguan cuaca terhadap curah hujan. Massa udara yang besar dan perubahan transpor kelembapan dapat menggeser tempat terbentuknya hujan. Transpor uap air merupakan jumlah uap air yang ditransfer per satu volume massa udara, dengan rentangan nilai transpor uap air yang berbeda-beda (Ardianto, 2014). Webster dan Fasullo (2003) menyebutkan salah satu yang mengendalikan mekanisme monsun adalah proses kelembapan. Proses transpor kelembapan di khatulistiwa terjadi ketika uap air bergerak dari utara ke selatan saat bulan Desember-Februari (DJF) (Syahidah, 2012).

Untuk mengetahui sumber daerah kelembapan dapat dihitung dengan transpor kelembapan vertikal (integrated moisture transport), menggunakan persamaan (Webster dan Fasullo, 2003):

$$
B q=\int_{0}^{\infty} q \tilde{V} d z
$$

Keterangan :

$\mathrm{Bq}$ : Transpor uap air vertikal rata-rata

$\mathrm{V} \quad$ : Vektor kecepatan angin horizontal pada ketinggian (z)

Q : Kelembapan spesifik pada ketinggian (z)

Pada lapisan 1000 mb di bulan Februari 2014, transpor uap air tertinggi terletak di Laut Cina Selatan di utara Kalimantan dengan rentangan nilai antara 600-1.000 Kg/ms-1. Sementara itu jumlah trasnpor uap air terendah terlihat di daratan Asia dan pantai barat Sumatera. Pada lapisan $1000 \mathrm{mb}$ dan lapisan $925 \mathrm{mb}$ tidak terlihat perubahan yang terlalu signifikan. Angin yang bergerak di Laut Cina Selatan pada lapisan 925 mb memiliki kecepatan yang lebih besar dibandingkan lapisan 1000 $\mathrm{mb}$. 


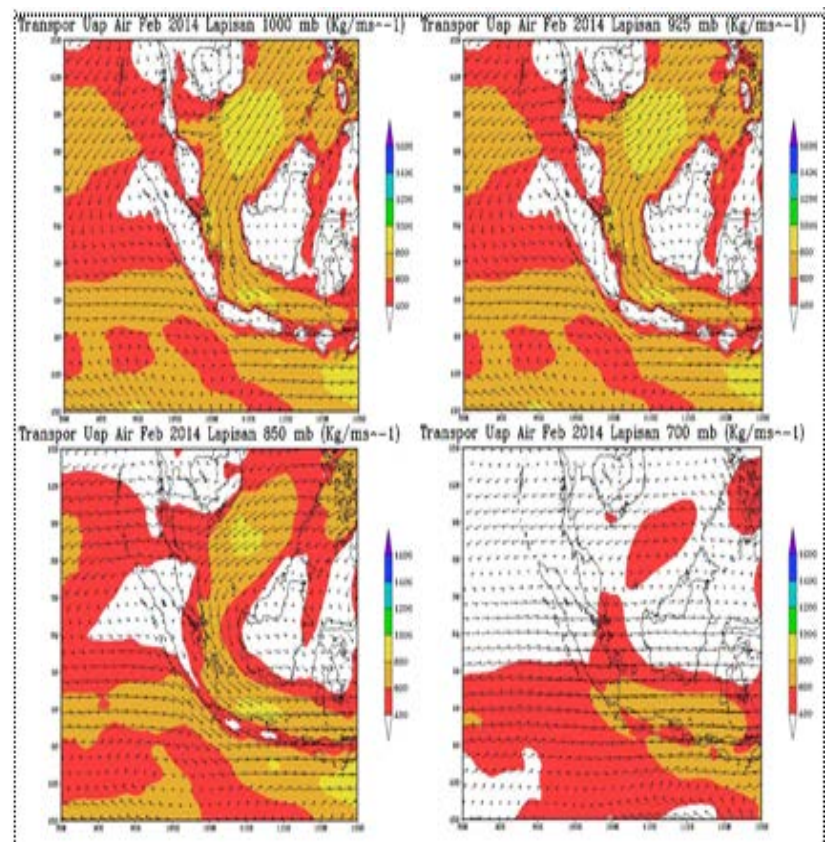

GAMBAR 6 Moisture Transport Februari 2014

Pada lapisan $850 \mathrm{mb}$ terlihat terjadi penurunan transpor uap air di wilayah Laut Cina Selatan maupun Samudera Hindia. Transpor uap air yang sampai ke Batam pada lapisan ini masih berasal dari Laut Cina Selatan dengan kisaran nilai yang cenderung sama, yaitu antara $400-800 \mathrm{Kg} / \mathrm{ms}^{-1}$. Semakin ke atas jumlah transpor uap air menjadi semakin berkurang. Pada lapisan $700 \mathrm{mb}$, terjadi penurunan jumlah transpor uap air yang sangat drastis di wilayah Asia dan Laut Cina Selatan. Jumlah transpor uap air yang tertinggi berada di Samudera Hindia yang berkisar antara 400-800 Kg/ms ${ }^{-1}$.

Di bawah ini akan dibahas perbandingan antara moisture transport pada bulan Februari 2014 dengan kondisi normalnya selama 30 tahun. Normal transpor uap air pada bulan Februari menunjukkan kondisi yang lebih basah daripada bulan Februari 2014. Normalnya, jumlah transpor uap air tertinggi terdapat di Laut Cina Selatan, di utara Kalimantan dengan rentangan nilai yang berkisar antara 1.000-1.600 Kg/ms ${ }^{-1}$. Tidak hanya di Laut Cina Selatan, jumlah transpor uap air di Samudera Hindia pada kondisi normlanya juga lebih tinggi daripada Februari 2014, dengan kisaran nilai antara $600-1.000 \mathrm{Kg} / \mathrm{ms}^{-1}$.

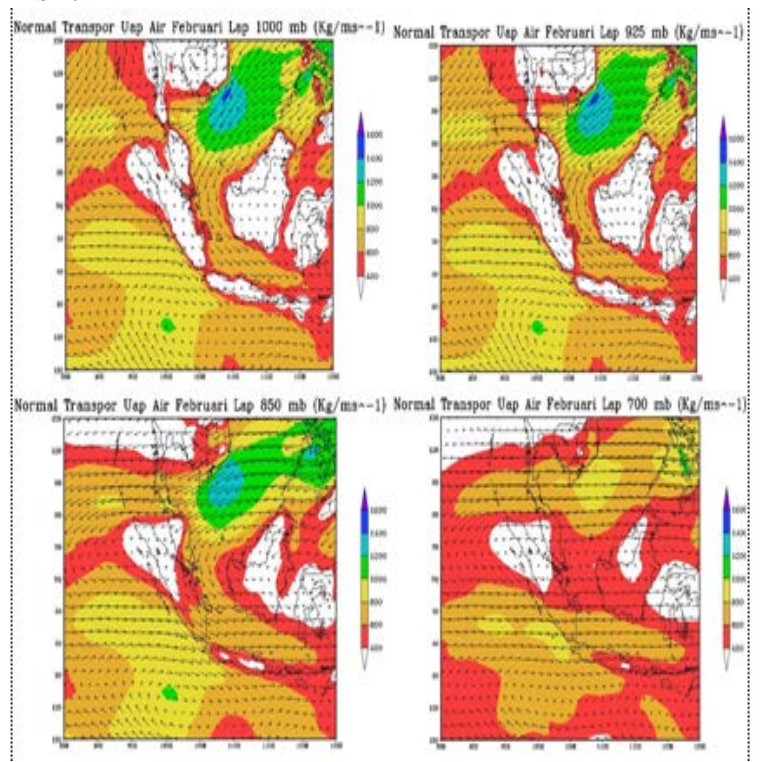

GAMBAR 7 Moisture Transport Dasarian II 
Pada lapisan 925 mb, kondisi transpor uap air cenderung sama dengan lapisan di bawahnya. Kondisi normal transpor uap air di lapisan $850 \mathrm{mb}$ juga tidak terlalu menunjukkan perubahan yang signifikan. Hanya saja pada lapisan ini terlihat penurunan transpor uap air di Laut Cina Selatan utara Kalimantan. Penurunan yang terjadi menyebabkan jumlah transpor uap air di wilayah tersebut berkisar antara 1.000-1.400 Kg/ms ${ }^{-1}$. Penurunan jumlah trasnpor uap air semakin terlihat pada lapisan $700 \mathrm{mb}$, jumlah trasnpor uap air tertinggi terlihat di Samudera Hindia dan Laut Cina Selatan dengan kisaran jumlah yang sama, yaitu $600-800 \mathrm{Kg} / \mathrm{ms}^{-1}$.

\section{KESIMPULAN}

Adapun kesimpulan yang dapat diambil dari analisis hasil penelitian yang telah dilakukan ialah :

a. Angin meridional yang berhembus dari daratan Asia dan Laut Cina Selatan menuju wilayah Indonesia, khususnya Indonsia bagian barat mengalami penurunan kecepatan, berkisar 5-10 m/s.

b. Angin meridional yang berhembus mengalami divergensi di wilayah Indonesia bagian barat, khususnya di antara Pulau Sumatera dan Kalimantan, akibatnya terjadi pemberaian massa udara di atas wilayah Indonesia, dan tidak mendukung untuk pertumbuhan awan-awan konvektif penghasil hujan.

c. Moisture transport pada bulan Februari 2014 jika dibandingkan dengan kondisi nornalnya mengalami penurunan. Dalam keadaan normal, kelembapan yang ditranspor dari daratan Asia, Laut Cina Selatan, dan Samudera Hindia menuju Indonesia sebesar 1.000-1.600 Kg/ms-1. Sedangkan pada Februari 2014 hanya berkisar 400-800 Kg/ms-1. Rendahnya transpor kelembapan dan uap air yang sampai di wilayah Indonesia bagian barat menyebabkan sulitnya pertumbuhan awan hujan di wilayah tersebut.

\section{REFERENSI}

[1] Ardianto, R., 2014, Transpor Uap Air Pada Borneo Vortex Serta PengaruhnyaTerhadap Curah Hujan, Skripsi, Program Sarjana Sains Terapan,Sekolah Tinggi Meteorologi Klimatologi dan Geofisika, Tangerang.

[2] Fasullo, J dan Webster, P,J, 2002, A Hydrological Definition of Indian Monsoon Onset and Withdrawel, University of Colorado, Colorado

[3] Prawoto, I., Azizah, N., dan Taufik, M., 2011, Tinjauan Kasus Banjir di Kepulauan Riau Akhir Januari 2011, Jurnal Megasains, Vol.2 No.2 - Juni 2011 Hal. 116 - 122. Sofiati, Iis, 2012, Karakteristik outgoing longwave radiation (OLR) berdasarkan Empirical Orthogonal Function (EOF) dan Kaitannya dengan Curah Hujan di Indonesia, LAPAN ,Jakarta

[4] Sribimawati, T., 1999, Climate Variability in Indonesia and Sea- Air-Land Interaction (ILUDWINA) Program., Oceanica -J. of Marine Sci. and Tech, BPPT, 5, 35-44

[5] Swarinoto, YS, 199,. Studi Tentang Aliran Lintas Equator pada Paras $850 \mathrm{mb}$ di Daerah Sekitar Laut Jawa, Skripsi Universitas Indonesia, Jakarta.

[6] Syahidah, M., 2012, Keterkaitan Borneo Vortex Terhadap Curah Hujan di Wilayah Indonesia Bagian Barat dan Tengah, Institut Teknologi Bandung, Bandung

[7] The European Centre for Medium-Range Weather Forecasts, 2015, [daring], http://apps.ecmwf.int/datasets/data/interim_full_daily/,diakses 22 Desember 2015 